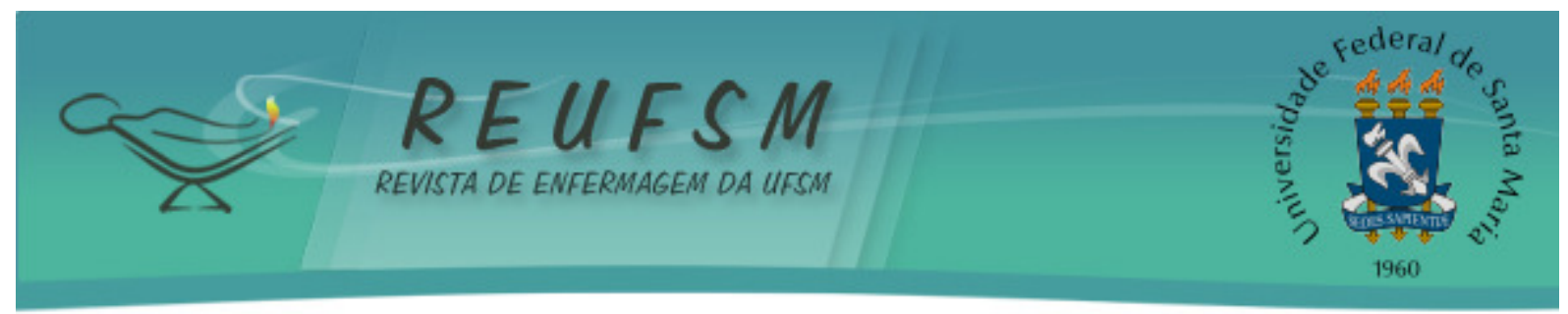

ARTIGO ORIGINAL

\title{
A CULTURA DA NÃO CONTENÇÃO DA PESSOA IDOSA - UMA NECESSIDADE, UM DIREITO, E UMA BATALHA ÉTICA E POLÍTICA
}

Fabio Cimador ${ }^{1}$

Doi: $10.5902 / 21797692133370$

No ambiente de saúde a contenção é definida como a limitação da possibilidade de movimento espontâneo e autônomo de um indivíduo através do uso de dispositivos variados. A contenção também existe no campo farmacológico e ambiental.

Esta prática fere os direitos humanos fundamentais, constitui uma violação das principais normas constitucionais de muitos países referentes à liberdade individual, além de ser contrária aos aspectos éticos e profissionais. ${ }^{1}$

$\mathrm{Na}$ literatura internacional os estudos de prevalência têm confirmado amplamente o uso sistemático dos meios de contenção. ${ }^{2}$ A prevalência ainda é muito elevada a nível internacional, sendo que nas últimas duas décadas diversos estudos tem demonstrado isso. Entretanto os dados exatos são difíceis de serem obtidos em função da grande diversidade metodológica utilizada nos estudos.

Nos últimos dez a quinze anos, intervenções visando reduzir a prática da contenção tem sido estimuladas, tanto nos diversos países-membro da União Européia e nos Estados Unidos, como também elas tem sido abordadas na Austrália. Mesmo em países que se encontram em situação de maior desenvolvimento econômico e que possuem um bom sistema sociossanitário (como Grã-Bretanha, França, Alemanha, entre outros) a prevalência do uso sistemático da contenção ainda permanece elevada.

As evidências científicas também demonstraram os danos e efeitos nocivos relacionados ao uso de meios de contenção como: agressividade, quedas, lesões por fricção, sofrimento psíquico, má nutrição, incontinência, entre outros. ${ }^{3}$ Desmascarando assim, as crenças não fundamentadas dos profissionais de saúde referentes à necessidade de contenção, pautada nos princípios da segurança da pessoa idosa.

0 idoso em situação de fragilidade ou que apresenta transtorno demencial é particularmente vulnerável a qualquer tipo de contenção e às muitas complicações que podem ser observadas, não somente no que se refere aos danos orgânicos mas também pelo componente emocional e psicológico.

Observa-se na atualidade que no Brasil, tanto quanto no restante da América Latina, ainda não existe uma conscientização por parte dos profissionais de saúde e dos órgãos de gestão e controle de que a contenção é causa de problemas sanitários graves. Assim, ela também está associada a custos elevados concomitantes aos prejuízos à capacidade funcional.

Em vista das previsões do aumento demográfico acelerado da população idosa no Brasil e na América Latina nos próximos anos, torna-se necessário e urgente que haja uma difusão ampla da Cultura de Não Contenção entre os profissionais de saúde no intuito de melhorar e otimizar os sistemas sociais e sanitários, garantindo a qualidade da assistência.

\footnotetext{
${ }^{1}$ Enfermeiro; Mestre em gestão e funções de coordenação dos profissionais de saúde pela Universidade La Sapienza - Roma; Coordenador das ILPIs conveniadas do distrito n1 da Secretaria de Saúde de Trieste, Itália; Professor da Escola para profissionais de saúde ENAIP de Trieste; Membro da Comissão de monitoramento e eliminação da contenção mecânica, farmacológica, ambiental e das más práticas profissionais assistências, velhas e novas; Presidente e cofundador do Grupo Internacional Tríplice Aliança - grupo focado na discussão de cuidados de longo prazo, cuidados de idosos em ILPIs e pela a difusão da cultura de não contenção. E-mail: fabiocimador@yahoo.it
} 


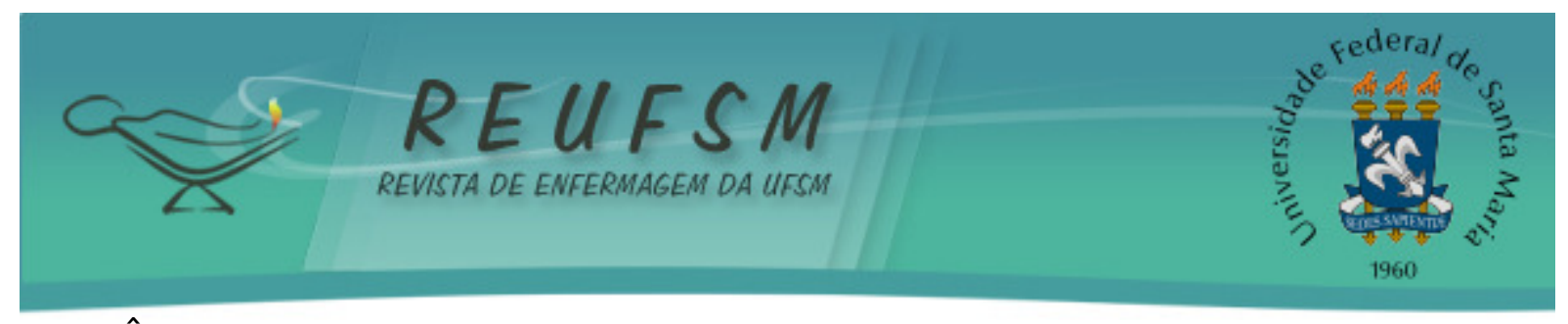

REFERÊNCIAS

1 Mislej M, Bicego L. Contro la contenzione. Garantire sempre, a ogni cittadino, l'articolo 13 della Costituzione. Si può, si deve. Maggioli Editore. 2011.

2 Zanetti E., Castaldo A., Miceli R., Magri M., Mariani L., Gazzola M., et al. L'utilizzo della contenzione fisica negli ospedali e nelle Residenze Sanitarie Assistenziali: indagine multicentrica di prevalenza. Rivista L'Infermiere [Internet]. 2012. Mar/Apr [cited 2017 Mar 06]; 56(2):6-26. Available from: http://www.ipasvi.it/ecm/rivista-linfermiere/rivistalinfermiere-page-8-articolo-97.htm

3 Menezes AK, Santana RF, Cimador F. Práticas assistenciais restritivas e o paradigma da cultura de não contenção da pessoa idosa. In: Freitas EV e Py L, organizadores. Tratado de Geriatria e Gerontologia. 4a ed., Rio de Janeiro: Guanabara Koogan; 2016, p.1267-76. 